\title{
An X-ray Study of Stacking Faults in Cu-Ge Alloys
}

\author{
(Received July 9, 1962)
}

An X-ray study was carried out on Copper-Germanium alloys in order to estimate the stacking fault probability and the stacking fault energy. Studies of stacking faults in several Copper alloys have been reported by several authors ${ }^{(1)}$, but the present experiment was done in more detail on Copper-Germanium alloys.

Within the assumption of the Paterson theory ${ }^{(2)}$, the stacking fault probability $(\alpha)$ was shown as follows ${ }^{(3)}$,

$$
\alpha=K\left(\delta 2 \theta_{\mathrm{ann}}-\delta 2 \theta_{\mathrm{c}_{\mathrm{W}}}\right),
$$

where $\delta 2 \theta_{\text {ann }}$ is a difference of $2 \theta$ between (111) and (200) X-ray reflection lines in an annealed state, and $\delta 2 \theta_{\mathrm{c}_{\mathrm{W}}}$ is the one in a cold worked state. The constant $K$ is 0.18 , when $\mathrm{Cu} K \alpha$ radiation is used. Moreover, the relation existing between the stacking fault probability and the energy $\left(r\right.$ erg $\left./ \mathrm{cm}^{2}\right)$ was shown as follows ${ }^{(4)}$,

$$
\alpha=\rho \cdot d\left[G\left(b_{1} \cdot b_{2}\right) \mid 2 \pi\right]=\text { const } \cdot G a(\rho / \gamma),
$$

where $\rho$ is the dislocation density, $d$ is the interplanar spacing of slip planes, which is proportional to the lattice parameter $a$, and $G$ is the shear modulus. $b_{1}$ and $b_{2}$ are Burger's vectors of two partial dislocations.

It can be assumed thet $\rho$ has a constant value independent of the composition of the solid solution range of the alloy system, when the alloys are heavily cold woiked. Further if assuming $G$ and $a$ to be constants for all compositions of the alloys, the stacking fault energy of the alloy can be approximately estimated, using $\alpha$ calculated from Eq. (1) and the stacking favlt energy of copper, $\gamma=$ $40 \mathrm{erg} / \mathrm{cm}^{2}$.

In the present experiment pure Copper and 'Copper alloy solid solutions containing 3.09, 5.32, 6.48 and 9.13 percent of Germanium respectively, were prepared and powdered by filing under Benzene at room temperature. The specimen temperature was kept as constant as possible filing. After filing, the powders were shifted using a 150 mesh sieve. The portion of the powders passing through the sieve were divided into six parts, the first part being placed in the sample holde: of the $\mathrm{X}$-ray equipment without further treatment. The remaining five portions weie annealed at $100^{\circ} \mathrm{C}, 150^{\circ} \mathrm{C}, 200^{\circ} \mathrm{C}$, $250^{\circ} \mathrm{C}$ and $300^{\circ} \mathrm{C}$, respectively, for 3 hours in vacuum and subjected to $\mathrm{X}$-ray analysis.

The peak positions of $\mathrm{X}$-ray diffraction were obtained by point counting across each peak, using a $G-E$ high angular goniometer equipped with a Geiger counter. Filtered $\mathrm{Co} K \alpha$ ray radiation was used. First the line profile was recorded, and second the count observation for a constant time at each $0.01^{\circ} \mathrm{C}$. Therefore, the error did not exceed $0.01^{\circ} \mathrm{C}$ for $2 \theta$.

Fig. 1 shows the separation between the (111) and (200) peaks in the case of a cold worked state, and also the those annealed at $100^{\circ} \mathrm{C}$ and $250^{\circ} \mathrm{C}$, respectively. The stacking fault probability $(\alpha)$, shown also in the figure, was calculated from Eq. (1), as in the method described above.

As seen in this figure, at $250^{\circ} \mathrm{C}$ annealing, the peak shift mostly recovered. Therefore, it may be understood that this curve of the figure corresponds to the ordinary separation of the annealed state. The change with the Germanium content is considered to be due to the difference of atomic diameters between Germanium and Copper.

(1) R. E. Smallman, K. H. Westmacott : Phil. Mag., 2 (1957), 669. P. Haasen, A. King: Z. Metallk., $12(1960), 155 ; \mathrm{K}$. Nakajima : SCI. REP. RITU, 12 (1960), 309; Trans. JIM., 2 (1961) 2.

(2) M. S, Paterson : J. Appl. Phys., 23 (1952), 805 ; B. E. Warren, E. P. Warekois : Acta Met., 3 (1955), 473.

(3) L. F. Vassamillet: J. Appl. Phys., 5 (1961), 778.

(4) A. H. Cottrell : Dislocation and Plastic Flow in Crystals, (1953).
However, in the case of cold working, the separation describes a parabolic curve for the Germanium content. It shows that the stacking fault density increases with the increase of Germanium.

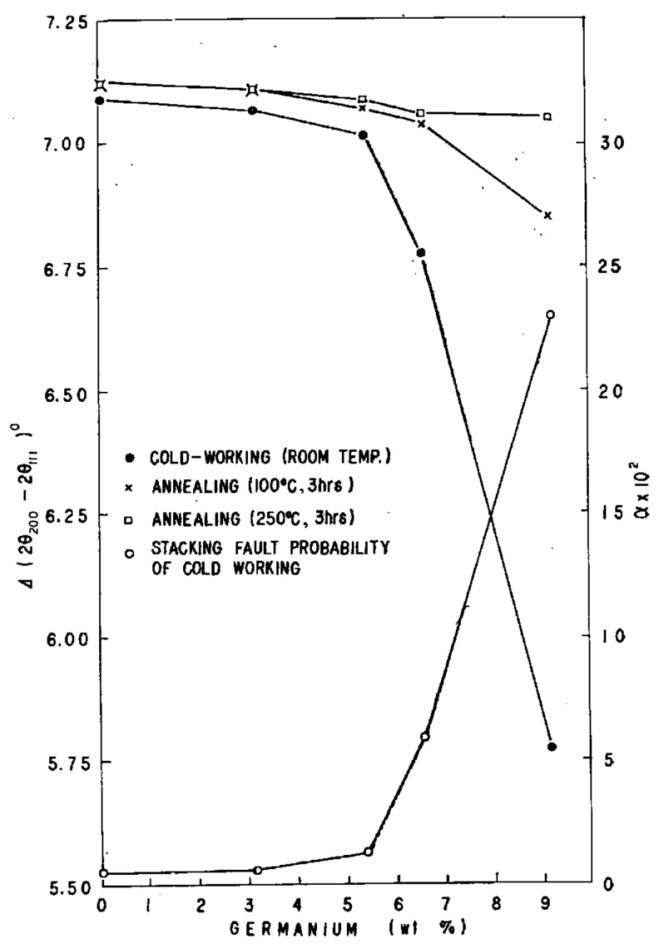

Fig. 1 The difference between (111) and (200) reflection lines.

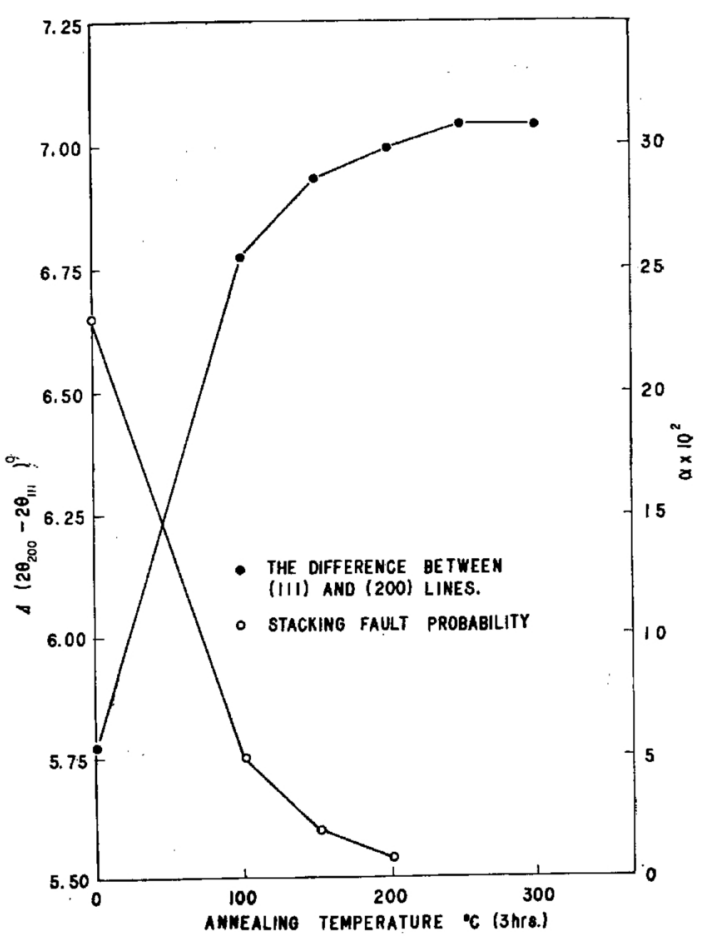

Fig. 2 The difference between (111) and (200) reflection. lines and the stacking fault probability for a coppergermanium $9.13 \%$ alloy. 
The cause can be considered that. the primary copper solid solution a Cu-Ge alloy system has a hexagonal phase to a neighboring plane, the solid solution will easily form stacking faults on the most packed (111) planes with the increase of Germanium. Naturally, the stacking fault probability increases with the increase of Germanium.

Fig. 2 shows the annealing dependence of the separation between two peaks and the stacking fault probability of an alloy with $9.13 \%$ Ge. Fig. 2 also shows that the shift shows 80 percent recovery by annealing at $100^{\circ} \mathrm{C}$ and recovery was completed when annealed at $250^{\circ} \mathrm{C}$ or $300^{\circ} \mathrm{C}$, when annealed for three hours. This phenomenon is due to the decrease of the stacking fault probalility with increasing annealing temperature.

In Fig. 3, the change of the stacking fault energy for Germanium content is shown. From this curve, it will be understood that the stacking fault energy decreases rapidly when approaching the solubility limit of the solid solution, which has a hexagonal phase to the neighboring phase. From the theoretical standpoint, the stacking fault energy can be considered to be due mainly to the electron energy in the Fermi surface. Therfore, the change of the stacking fault energy of the alloys should be studied from the effect of solute atoms to the Fermi surface of the alloys.
In the present result, the stacking fault energy of a $\mathrm{Cu}-\mathrm{Ge} 9.13 \%$ alloy was about $0.88 \mathrm{erg} / \mathrm{cm}^{2}$. At such a low value, all dislocation

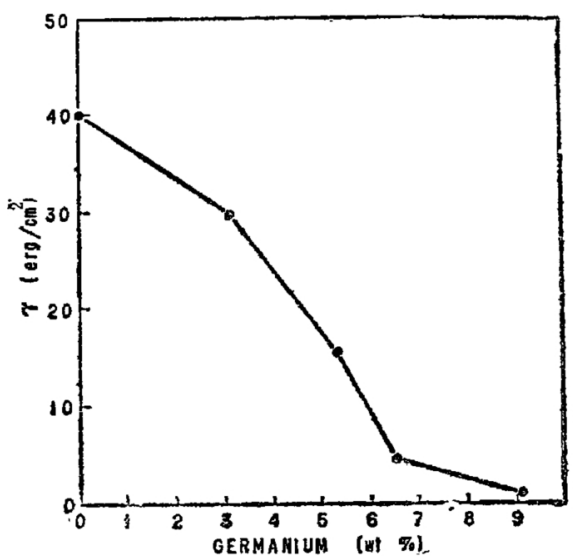

Fig. 3 Stacking fault energy.

might be extended by a small internal stress. Possibly this can be proven by direct observation using an electron microscope.

By Koji Nomaki and Shigeyasu Koda

(Research Institute for Irom, Steel and Other Metals, Tohoku University, 75, Katahiracho, Sendai, Japan) 